Received 08/04/2021 Review began 08/25/2021 Review ended 09/09/2021 Published 09/11/2021

(c) Copyright 2021

Sandhu et al. This is an open access article distributed under the terms of the Creative Commons Attribution License CC-BY 4.0., which permits unrestricted use, distribution, and reproduction in any medium, provided the original author and source are credited.

\section{Oxidative Stress in Polycystic Ovarian Syndrome and the Effect of Antioxidant N-Acetylcysteine on Ovulation and Pregnancy Rate}

Jasmine K. Sandhu ${ }^{1}$, Ahsan Waqar ${ }^{2}$, Ashish Jain ${ }^{3}$, Christine Joseph ${ }^{4}$, Kosha Srivastava ${ }^{5}$, Olive Ochuba ${ }^{3}$, Tasnim Alkayyali ${ }^{6,7}$, Sheila W. Ruo ${ }^{8}$, Sujan Poudel ${ }^{9}$

1. Obstetrics and Gynecology, California Institute of Behavioral Neurosciences \& Psychology, Fairfield, USA 2. Family Medicine, California Institute of Behavioral Neurosciences \& Psychology, Fairfield, USA 3. Internal Medicine, California Institute of Behavioral Neurosciences \& Psychology, Fairfield, USA 4. Urology/Obstetrics and Gynecology, California Institute of Behavioral Neurosciences \& Psychology, Fairfield, USA 5. Neurology, California Institute of Behavioral Neurosciences \& Psychology, Fairfield, USA 6. Internal Medicine, Marmara University, Istanbul, TUR 7. Pathology, California Institute of Behavioral Neurosciences \& Psychology, Fairfield, USA 8. General Surgery, California Institute of Behavioral Neurosciences \& Psychology, Fairfield, USA 9. Psychiatry and Behavioral Sciences, California Institute of Behavioral Neurosciences \& Psychology, Fairfield, USA

Corresponding author: Jasmine K. Sandhu, jasminesandhu01@yahoo.com

\title{
Abstract
}

Polycystic ovarian syndrome (PCOS) is an endocrinological condition that leads to infertility in many females. $\mathrm{N}$-acetylcysteine (NAC), a novel antioxidant, is being used as an adjuvant to treat infertility in females suffering from PCOS. This review aims to evaluate oxidative stress in females suffering from PCOS and assess whether the anti-oxidizing properties of NAC are beneficial in enhancing the rate of ovulation and pregnancy in infertile PCOS females. A literature search was conducted manually on PubMed and Google Scholar databases using the following keywords: "N-Acetylcysteine," "PCOS," "Oxidative stress," "Antioxidants," and "infertility" alone and/or in combination for data collection. The studies were manually screened and, after applying inclusion-exclusion criteria, 32 studies consisting of 2466 females of the reproductive age group are included in this review. Our review revealed that females suffering from PCOS tend to show elevated levels of inflammatory markers and a decrease in antioxidant capacity. When used in combination with clomiphene citrate or letrozole, NAC increases ovulation and pregnancy rate in infertile females suffering from PCOS and positively affects the quality of oocytes and number of follicles $\geqslant 18 \mathrm{~mm}$. Moreover, its side effect profile is low. It also results in a mild increase in endometrial thickness in some females. Future studies on a large sample size using NAC alone are highly recommended to evaluate its role as a single-drug therapy for treating infertility in females suffering from PCOS.

Categories: Endocrinology/Diabetes/Metabolism, Obstetrics/Gynecology

Keywords: n-acetylcysteine, pcos, oxidative stress, antioxidants, infertility

\section{Introduction And Background}

Polycystic ovarian syndrome (PCOS) is a multi-system endocrinological disorder affecting females of the reproductive age group characterized by clinical and biochemical abnormalities such as menstrual irregularities, hyperandrogenism, infertility, hyperinsulinemia, and multiple ovarian cysts. In recent years, the incidence of PCOS is rapidly growing due to changes in lifestyle, diet, and stress. Its prevalence is variable, ranging from $2.2-2.6 \%$, and has affected 116 million females globally, according to WHO estimates in 2012 [1]. A survey conducted in India in 2020 showed that $16 \%$ and $11 \%$ of females in the age groups 20 29 years and 30-44 years, respectively, suffer from PCOS [2].

PCOS is diagnosed using the Rotterdam Criteria-2003, which includes two of the following features: oligo/amenorrhea, anovulation, infertility; hyperandrogenism (clinical or biochemical signs and symptoms); and polycystic ovaries (12 or more) [3]. It may be set in early adolescent life but clinically manifests in childbearing age with long-term complications such as type 2 diabetes mellitus, hypertension, hyperlipidemia, endometrial cancer, and cardiovascular disorders [4]. Early identification and treatment can help mitigate some of these adverse metabolic effects. PCOS is a multifactorial disorder caused by both genetic and environmental factors. It is mainly seen in obese females with resultant insulin resistance [5]. Hyperinsulinemia elevates luteinizing hormone (LH), which then induces thecal cell hyperplasia resulting in androgen overproduction. Androgens inhibit hepatic production of sex hormone-binding globulin (SHBG), leading to increased free testosterone levels in the body, as illustrated in Figure 1, which present clinically as excessive facial hair and acne [4]. Androgens also inhibit the growth of the dominant follicle and prevent apoptosis of smaller follicles leading to cyst formation in the ovaries. The hormonal imbalances seen in females with PCOS are decreased follicle-stimulating hormone (FSH) and FSH/LH ratio, increase in the level of $\mathrm{LH}$, fasting insulin, estrogen, free testosterone, and a mild increase in prolactin [4]. 


\section{Cureus}

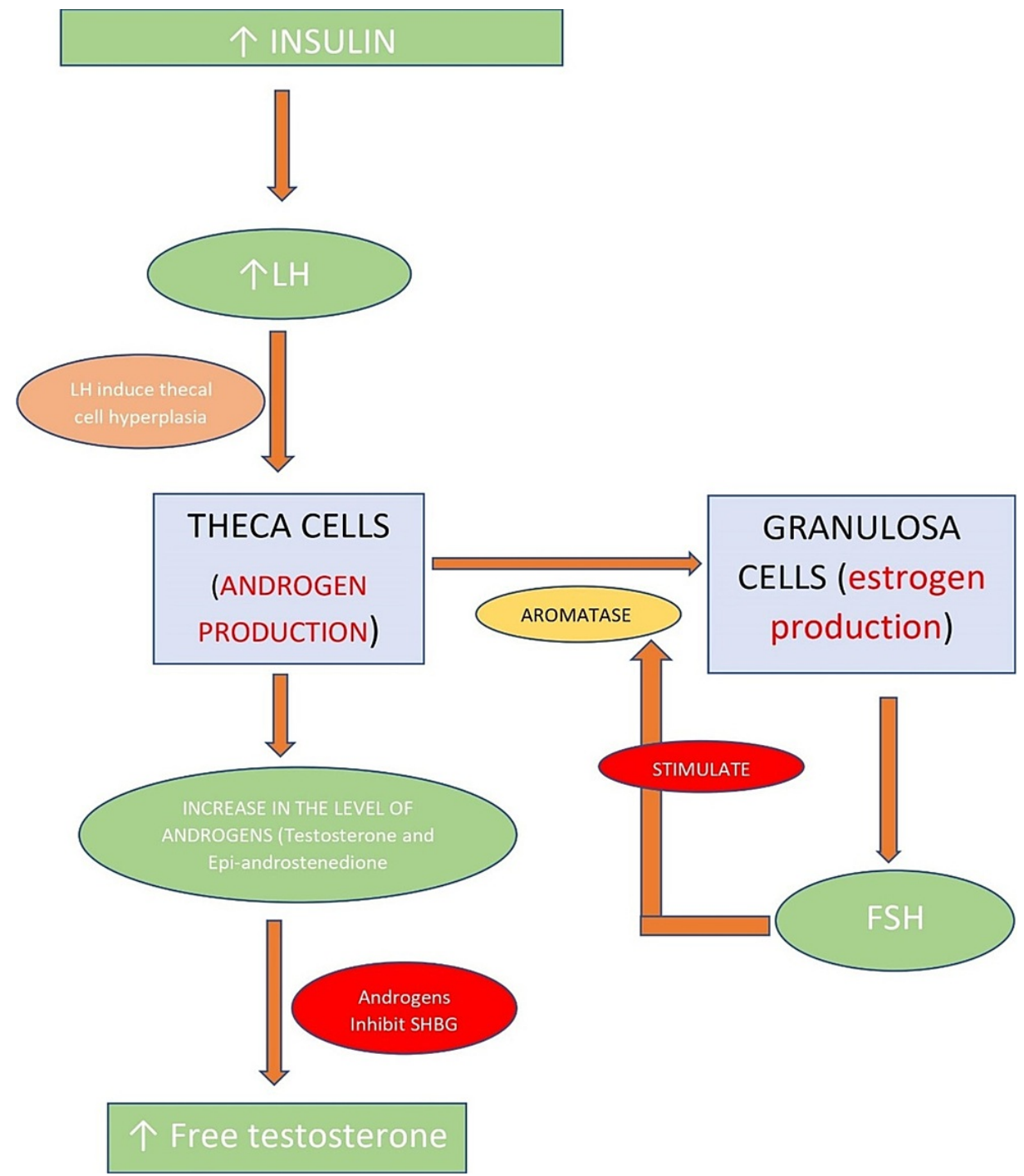

FIGURE 1: Sequence of events in the pathogenesis of PCOS

LH: luteinizing hormone; FSH: follicle-stimulating hormone; SHBG: sex hormone-binding globulin

Lifestyle changes such as weight loss and smoking cessation are effective in treating PCOS. Additionally, oral contraceptives, FSH, LH, and gonadotropin-releasing hormone ( $\mathrm{GnRH}$ ) analogs, metformin, letrozole, and laparoscopic ovarian drilling (LOD) are also used to treat PCOS. Metformin, an insulin-sensitizing agent, is extremely helpful in obese females with insulin resistance [4]. Infertility is a significant problem faced by females suffering from PCOS. It is defined as an inability to conceive after a year of regular and unprotected intercourse [6]. About $20 \%$ of infertility is attributed to anovulation caused by PCOS [4]. Various treatment modalities are employed to cure infertility, but the success rate remains low. Clomiphene citrate (CC) is the first line of treatment to induce ovulation, but it is futile in many patients, along with ovarian hyperstimulation syndrome (OHS) seen in $10 \%$ of cases [4]. Recently, antioxidants such as $\mathrm{N}$-acetylcysteine (NAC), Myo-inositol, and micronutrients have been used in addition to the above medications to improve the chances of getting pregnant [4].

NAC, the N-acetyl derivative of natural amino acid L-cysteine, is a known antioxidant [7]. It has been commonly used for acetaminophen toxicity and as a mucolytic for decades [7]. It has also been used to treat cystic fibrosis, atherosclerosis and its complications, and malignancy [8]. There are several theories behind the mechanism of action of NAC. First, it interacts with electrophilic groups and scavenges free radicals such as hydrogen peroxide and superoxide with the help of its thiol side chain [7,9]. Second, it acts as a source of cysteine (Cys) for glutathione (GSH) synthesis and, third, it breaks disulfide linkages, hence acting as a mucolytic $[7,9]$. The elevated glutathione levels in the cells result in insulin binding to carrier proteins, which helps glucose uptake and utilization [8]. This leads to a decrease in insulin levels and thus alleviates the leading cause of PCOS. The antioxidant properties of NAC have been utilized in multiple clinical trials conducted on infertile PCOS females to improve oocyte quality and enhance pregnancy and ovulation rate [8]. 
This literature review aims to provide information on the effectiveness of NAC on oocyte quality, follicular size, pregnancy, and ovulation rate in infertile females suffering from PCOS. The PubMed and Google Scholar databases were searched manually using the following keywords: "N-Acetylcysteine," "PCOS," "Oxidative stress," "Antioxidants," and "Infertility" alone and/or in combination to find studies relevant to the topic of research. A total of 1957 studies were obtained, which were later screened based on title and abstract. We included systematic reviews, traditional reviews, randomized control trials (RCT), clinical trials, case-control studies, cross-sectional studies, and books. We included only those studies from Google Scholar published in the last three years (2018-2021). This review article excluded animal studies, grey literature, case series, case reports, and studies on the male population. Thirty-two studies consisting of 2466 females are included in this review after applying inclusion-exclusion criteria, including information from a book and websites. The study consists of two systematic reviews, 12 traditional reviews, seven RCTs, two controlled clinical trials, seven case-control studies, and two cross-sectional studies.

\section{Review}

\section{Oxidative stress and PCOS}

Oxidative stress is defined as an imbalance in the level of oxidants and antioxidants in the body and is measured with the help of the following parameters: total antioxidant status (TAS), total oxidant status (TOS), and oxidative stress index (OSI) [10]. OSI is the percentage ratio of TOS to TAS [10]. Oxidantantioxidant imbalance is seen in females suffering from PCOS, and this oxidative stress is due to various metabolic abnormalities such as obesity, hyperinsulinemia, and dyslipidemia [11]. Obesity is seen in 40-50\% of females with PCOS, which results in lipid catabolism and free radical production, ultimately leading to oxidative stress [12]. Hyperglycemia results in an increased reactive oxygen species (ROS) generated from mononuclear cells [13]. ROS are oxygen-free radicals produced by reducing molecular oxygen and generated as byproducts of aerobic respiration and metabolism [13]. ROS plays a crucial role in various bodily functions by regulating cell growth, differentiation, progression, and cell death and, thus, their balance is required in the body. ROS results in activation of tumor necrosis factor-alpha (TNF- $\alpha$ ) and an increase in the level of nuclear factor-kappa B (NF-KB), an inflammatory transcription factor [13]. Inflammatory markers stimulate androgen production in ovaries leading to hyperandrogenism and, thus, links PCOS with inflammation [14]. TNF- $\alpha$ is a known mediator of insulin resistance [15]. Therefore, a vicious cycle is created in the ovarian epithelium, resulting in the formation of cysts, low-quality ovarian follicles, and infertility [13]. Antioxidant enzymes such as superoxide dismutase (SOD), catalase, and glutathione peroxidase protect cells against toxic ROS. Studies conducted on females with PCOS showed alterations in the levels of inflammatory markers, some of the above-mentioned protective enzymes, and antioxidant status compared to females with no ovarian pathology.

A case-control study conducted by Enechukwu et al. on 50 PCOS patients revealed a significant decrease in the total antioxidant capacity (TAC) $(\mathrm{p}<0.001)$ and activity of SOD $(\mathrm{p}<0.001)$ when compared with 50 females with normal ovarian function [16]. Moreover, there was a significant elevation in the level of malondialdehyde (MDA) [16]. MDA, a known marker of oxidative stress, is the final product of polyunsaturated fatty acid peroxidation [17]. Another case-control study by Bannigida et al. on 100 PCOS patients also revealed a significant elevation in MDA levels $(\mathrm{p}<0.001)$ compared to 100 females in the control group [18]. A case-control study by Shahrokhi and Naeni compared the level of TAC and MDA in 60 females with PCOS to 90 healthy females [12]. The results showed no statistically significant difference in the mean TAC between the two groups; however, MDA levels were significantly higher in PCOS patients [12]. A casecontrol study by Sak et al. on 94 females (46 PCOS females and 48 healthy controls) revealed that TOS and OSI are significantly higher in the PCOS group compared to control ( $\mathrm{p}=0.002$ and $\mathrm{p}=0.004$ respectively) [10]. It also showed a significant decrease in TAS in the PCOS group [10]. A study by Liu et al. also showed significantly higher levels of TOC $(\mathrm{p}<0.001)$ and OSI in the PCOS group compared to the control [19]. A casecontrol study by Sulaiman et al. showed a higher level of glutathione peroxidase, and glutathione reductase in 51 females with PCOS ( $>>0.05$ ) compared to 45 healthy females [20]. It also showed lower level of glutathione ( $p=0.006)$ and TAC ( $>>0.05)$ in PCOS group [20]. A study by Jeelani et al. also showed a significant increase in the level of MDA and SOD and a decrease in TAC in 95 females suffering from PCOS compared to the control group [21]. A cross-sectional study conducted by Artimani et al. on 21 females with PCOS undergoing Intracytoplasmic sperm injection (ICSI) showed a higher concentration of follicular fluid levels of inflammatory markers including interleukin-6 (IL-6), IL-8, and TNF- $\alpha$ and lower concentrations of IL-10, an anti-inflammatory interleukin compared to the control group [14]. Moreover, the level of TAC and Thiol groups were lower in the PCOS group [14]. Another cross-sectional study by Moti et al. on 30 females suffering from PCOS also revealed decreased total antioxidants in PCOS patients compared to 30 females with normal ovarian function [22].

The findings of the studies show that chronic inflammation and oxidative stress are one of the causative factors of PCOS. The elevated levels of oxidative markers further aggravate the pro-inflammatory status in PCOS females [21]. To treat females suffering from PCOS, we need a drug with the capacity to modulate the levels of inflammatory markers and antioxidants. NAC elevates the level of glutathione, a known antioxidant and, thus, increases total antioxidant capacity. In addition, the thiol-free side chain of NAC increases the level of thiol in females treated with NAC. NAC acts as an anti-inflammatory molecule by scavenging free radicals such as hydrogen peroxide and superoxide and inhibiting the release of TNF- $\alpha$ and other interleukins from phagocytic cells by down-regulating the activity of NF-KB [8]. Hence, it lowers 


\section{Cureus}

inflammation and oxidative stress in the ovarian epithelium.

\section{Effect of NAC on oocyte quality}

Meiotic and cytoplasmic maturation of oocytes is negatively impacted by inflammation and oxidative stress, which results in decreased fertilization and implantation [23]. A negative correlation is seen with TOC and high-quality embryo and blastocyst formation in the PCOS group in a case-control study by Lei et al. $(p<0.05)$ [19]. Another study by Lei et al. on infertile females undergoing in vitro fertilization and embryo transfer (IVF-ET) showed that females suffering from PCOS have lower fertilization, clinical pregnancy, implantation rate, and a higher rate of miscarriage compared to females with tubal factor infertility $(p>0.05)$ [24]. Moreover, ROS in granulosa cells is significantly higher $(\mathrm{p}<0.05)$ in the PCOS group [24]. The increased ROS in PCOS females leads to increased apoptosis of granulosa cells, which affects the oocyte quality and, hence, reduces the effectiveness of IVF-ET pregnancy results in females suffering from PCOS [24]. Oocytes require various growth factors for proper growth and maturation of follicles during reproductive cycles. The primary oocyte-secreted factors (OSFs) are growth differentiation factor-9 (GDF-9) and bone morphogenic factor-15 (BMF-15) [25]. These factors can be used to evaluate the quality of oocytes [25]. C-kit is another OSF and studies show a relationship between c-kit with mitogen-activated protein kinases (MAPK) pathway and phosphoinositide 3-kinase (P13K) pathway essential in the development of follicles [26]. A double-blind placebo-controlled clinical trial was conducted in the IVF unit in Iran on 80 females aged 25-35 years diagnosed with PCOS based on the Rotterdam criteria planning to undergo ICSI. The subjects were divided into four groups, with 20 patients in each group. Group one received a placebo; Group two received metformin (MET); Group three received NAC, and Group four received MET + NAC. Results revealed a significant elevation in the expression of GDF-9 and a decrease in expression of c-kit in unfertilized mature oocytes in the patients receiving NAC compared to other groups. The study concluded that NAC interferes with the MAPK pathway and thus decreases c-kit levels [25]. Additionally, the antioxidant nature of NAC has an inhibitory effect on NF-KB and, thus, increases the expression of GDF-9. A similar study by Cheraghi et al. on 60 PCOS women in Iran showed a significant decrease in the number of abnormal and immature oocytes and an increase in healthy oocytes $(\mathrm{p}<0.05)$ in the NAC recipients [27]. There was also a significant decrease in the level of MDA in NAC patients $(\mathrm{p}<0.02)$ [27].

These studies show that NAC has a positive effect on the growth and maturation of oocytes and hence, can improve pregnancy rates by producing good quality oocytes for fertilization. Therefore, we could employ Nacetylcysteine's impact on these ovarian factors to improve the quality of oocytes in females suffering from PCOS.

\section{Effect of NAC on ovulation and pregnancy}

To evaluate the effect of NAC on ovulation and pregnancy rate, we assessed seven RCTs, out of which four were double-blind studies [28-34]. The studies consisted of a total of 1207 females suffering from PCOS diagnosed based on the Rotterdam criteria. The trials were conducted by randomly dividing people into different treatment groups receiving either clomiphene citrate or letrozole along with NAC or a placebo to compare the effectiveness of NAC (Table 1). 


\section{Cureus}

\begin{tabular}{|c|c|c|c|c|c|c|}
\hline $\begin{array}{l}\text { STUDY } \\
\text { ID }\end{array}$ & $\begin{array}{l}\text { STUDY } \\
\text { TYPE }\end{array}$ & PERIOD & COUNTRY & $\begin{array}{l}\text { NUMBER } \\
\text { OF } \\
\text { PATIENTS }\end{array}$ & TREATMENT & INCLUSION CRITERIA \\
\hline $\begin{array}{l}\text { leImourı } \\
\text { et al. [28] }\end{array}$ & RCI & 2018 & Iran & 317 & $\begin{array}{l}\text { Group A: letrozole } 5 \mathrm{mg} \\
+ \text { NAC } 1200 \mathrm{mg} \text {; Group } \\
\text { B: letrozole } 5 \mathrm{mg}\end{array}$ & $\begin{array}{l}\text { Presence of PCOS, normal thyroid } \\
\text { hormones and prolactin levels, infertility } \\
\text { duration of at least one year, one patent } \\
\text { fallopian tube, normal semen analysis of } \\
\text { partner }\end{array}$ \\
\hline $\begin{array}{l}\text { Hassan et } \\
\text { al. [29] }\end{array}$ & RCT & $\begin{array}{l}\text { April } 2018- \\
\text { Jan } 2019\end{array}$ & Egypt & 150 & $\begin{array}{l}\text { Group A: CC } \\
(100 \mathrm{mg} / \text { day })+\mathrm{NAC} \\
(1.2 \mathrm{~g} / \text { day); Group B: } \\
\text { CC (100mg/day) }+ \\
\text { placebo (ORS) }\end{array}$ & $\begin{array}{l}\text { Presence of PCOS, both fallopian tubes } \\
\text { patent, normal semen analysis of partner }\end{array}$ \\
\hline $\begin{array}{l}\text { Mostajeran } \\
\text { et al. [30] }\end{array}$ & $\begin{array}{l}\text { Double- } \\
\text { blind RCT }\end{array}$ & 2015-2016 & Iran & 130 & $\begin{array}{l}\text { Group A: letrozole } 5 \mathrm{mg} \\
+ \text { + NAC } 1200 \mathrm{mg} ; \\
\text { Group B: letrozole } 5 \mathrm{mg} \\
+ \text { placebo (ORS) }\end{array}$ & $\begin{array}{l}\text { Presence of PCOS, age } 20-35 \text { years, BMI } \\
<35 \mathrm{~kg} / \mathrm{m}^{2} \text {, patent fallopian tubes, normal } \\
\text { semen values of partner }\end{array}$ \\
\hline $\begin{array}{l}\text { Maged et } \\
\text { al. [31] }\end{array}$ & RCT & $\begin{array}{l}\text { September } \\
2012 \text { - } \\
\text { March } \\
2014\end{array}$ & Egypt & 120 & $\begin{array}{l}\text { Group A: CC only; } \\
\text { Group B: CC + NAC; } \\
\text { Group C: CC + MET }\end{array}$ & $\begin{array}{l}\text { Presence of PCOS diagnosed on the basis } \\
\text { of Rotterdam Criteria }\end{array}$ \\
\hline $\begin{array}{l}\text { Salehpour } \\
\text { et al. [32] }\end{array}$ & $\begin{array}{l}\text { Double- } \\
\text { blind } \\
\text { placebo- } \\
\text { controlled } \\
\text { RCT }\end{array}$ & $\begin{array}{l}\text { Jan } 2008- \\
\text { Dec } 2009\end{array}$ & Iran & 180 & $\begin{array}{l}\text { Group A: CC } \\
(100 \mathrm{mg} / \text { day })+\text { NAC } \\
(1.2 \mathrm{~g} / \text { day }) ; \text { Group B: } \\
\mathrm{CC}(100 \mathrm{mg} / \text { day })+ \\
\text { placebo }\end{array}$ & $\begin{array}{l}\text { Presence of PCOS diagnosed on the basis } \\
\text { of Rotterdam Criteria }\end{array}$ \\
\hline Nasr A [33] & $\begin{array}{l}\text { Double- } \\
\text { blind } \\
\text { placebo- } \\
\text { controlled } \\
\text { RCT }\end{array}$ & $\begin{array}{l}\text { Jan } 2005- \\
\text { June } 2007\end{array}$ & Egypt & 60 & $\begin{array}{l}\text { Group A: NAC } \\
\text { (1.2g/day); Group B: } \\
\text { placebo }\end{array}$ & $\begin{array}{l}\text { Females with CC-resistant PCOS who } \\
\text { underwent unilateral LOD }\end{array}$ \\
\hline $\begin{array}{l}\text { Rizk et al. } \\
{[34]}\end{array}$ & $\begin{array}{l}\text { Double- } \\
\text { blind } \\
\text { placebo- } \\
\text { controlled } \\
\text { RCT }\end{array}$ & $\begin{array}{l}\text { March } \\
2002 \text { - Nov } \\
2003\end{array}$ & Egypt & 150 & $\begin{array}{l}\text { Group A: CC } \\
\text { (100mg/day) + NAC } \\
\text { CC (100mg/day })+ \\
\text { placebo }\end{array}$ & $\begin{array}{l}\text { Females with CC-resistant PCOS } \\
\text { undergoing infertility treatment, Age 18-39 } \\
\text { years }\end{array}$ \\
\hline
\end{tabular}

\section{TABLE 1: Characteristics of studies included: type, period, country, number of patients,}

treatment, and inclusion criteria.

RCT: randomized controlled trial; NAC: N-acetylcysteine; CC: clomiphene citrate; MET: metformin; PCOS: polycystic ovarian syndrome; ORS: oral rehydration solution; LOD: laparoscopic ovarian drilling

An RCT by Teimouri et al. was conducted in Iran [28]. Treatment was administered for five days to 317 infertile females suffering from PCOS, following which 5000 units of human chorionic gonadotropin (hCG) were injected intramuscularly if a minimum of one follicle measured $\geqslant 18 \mathrm{~mm}$ on vaginal ultrasound. They were advised to have intercourse, and on the 12th day after the injection, the level of $\beta$-hCG was checked to assess for pregnancy. Results showed a statistically significant increase in pregnancy rate in NAC-treated patients $(\mathrm{p}=0.046$ ). Twenty-three females (14.6\%) got pregnant in group A (NAC-treated) compared to 12 females (7.5\%) in group B in the trial. There was no statistically significant change in follicular size and endometrial thickness in the intervention group [28]. An RCT was conducted by Hassan et al. on 150 females suffering from PCOS diagnosed based on the Rotterdam criteria [29]. The females were injected with 10,000 units of hCG on the 12th day of the cycle. The results showed a significant increase in ovulation (Group A (NAC treated): 40\% v/s Group B: $24 \%$ ) and pregnancy rate $(\mathrm{p}=0.007)$ in females receiving NAC. Twenty-eight females (18.7\%) got pregnant in group A compared to 12 females (8\%) in group B [29]. Mostajeran et al. conducted a double-blind RCT on 130 females to study the effect of adding NAC to letrozole for treating PCOS [30]. Results revealed a significant increase in ovulation rate $(\mathrm{p}=0.032)$ and pregnancy rate $(\mathrm{p}=0.045)$. Twelve females got pregnant in group A (NAC treated) compared to four females in group B [30]. Moreover, 
the size of follicles is also significantly improved in NAC treated group ( $p=0.007)$ [30]. Another RCT by Maged et al. also showed similar results concerning follicular size, ovulation rate, and pregnancy rate $(\mathrm{p}<0.05)$ in females treated with NAC [31].

Salehpour et al. conducted a placebo-controlled double-blind RCT on 180 females. Results showed a significant increase in follicular size (number of follicles $\geqslant 18 \mathrm{~mm})(\mathrm{p}<0.001)$, mean endometrial thickness $(\mathrm{p}<0.001)$, ovulation rate $(\mathrm{p}=0.02)$, and pregnancy rate $(\mathrm{p}=0.04)$, along with zero cases of OHS [32]. Two more placebo-controlled double-blind RCTs were conducted in Egypt on females with CC-resistant PCOS [33,34]. There was a significant increase in ovulation rate ( $\mathrm{p}<0.01$ ) (Group A (NAC treated): 87\% v/s Group B: 67\%), pregnancy rate ( $\mathrm{p}<0.01$ ) (Group A: 77\% v/s Group B: $57 \%$ ), and live birth rate, and fewer miscarriages in females receiving NAC after LOD in the RCT conducted by Nasr A [33]. The other trial was conducted by Rizk et al. on 150 females with CC-resistant PCOS who also showed improvement in ovulation and pregnancy rate (21.3\% got pregnant in group A (NAC treated) compared to zero in group B) along with no cases of OHS with NAC [34].

All the clinical trials showed statistically significant improvement in pregnancy $(\mathrm{p}<0.05)$, and six trials showed a substantial increase in the rate of ovulation $(\mathrm{p}<0.05)$ in females treated with NAC [28-34]. The dominant follicle should be of the appropriate size $(\geqslant 18 \mathrm{~mm})$ for fertilization to occur. Four out of eight studies showed a significant increase in the number of follicles $\geqslant 18 \mathrm{~mm}$ in size in the intervention group, and one study had higher appropriately sized follicles in the control group [30-32]. The thickness of the endometrium is another factor determining the success of pregnancy as implantation of blastocyst only takes place in the uterus if the endometrium is of appropriate thickness. Three studies showed a statistically significant increase in endometrial thickness in the females receiving NAC, and one study showed no difference in both groups. Based on these studies, we concluded that NAC serves as an effective treatment modality for infertility issues in females suffering from PCOS.

A systematic review and meta-analysis of RCTs were also conducted by Thakker et al. in 2014 on 910 females to review the drawbacks and benefits of NAC in women with PCOS [35]. The review concluded that the ovulation and pregnancy rate was three times higher in NAC recipients than in non-NAC recipients, with a higher live birth rate and fewer side effects in the former. However, the studies included were of shorter duration (three months) with a limited number of patients and wide confidence intervals [35].

\section{Conclusions}

Females suffering from PCOS show an increase in the level of inflammatory markers in addition to decreased levels of antioxidants. $\mathrm{N}$-acetylcysteine shows promising results in restoring this oxidative balance and promoting high-quality oocytes with appropriate follicular size. It also increases ovulation and pregnancy rate with fewer side effects such as ovarian hyperstimulation syndrome, commonly seen with other medications. However, most of the trials included in this review were done on a small population group, and NAC was used as an additive to letrozole and clomiphene in treating infertility in PCOS patients. Therefore, there is a need to conduct clinical trials on a large sample size to show better efficacy results. In addition, since the NAC-treated group also has a low side effect profile compared to other groups, tests should be conducted to assess the effect of this drug as single-drug therapy in the future instead of being used as an adjuvant to other medications.

\section{Additional Information \\ Disclosures}

Conflicts of interest: In compliance with the ICMJE uniform disclosure form, all authors declare the following: Payment/services info: All authors have declared that no financial support was received from any organization for the submitted work. Financial relationships: All authors have declared that they have no financial relationships at present or within the previous three years with any organizations that might have an interest in the submitted work. Other relationships: All authors have declared that there are no other relationships or activities that could appear to have influenced the submitted work.

\section{References}

1. Bharathi RV, Swetha S, Neerajaa J, et al.: An epidemiological survey: effect of predisposing factors for PCOS in Indian urban and rural population. Middle East Fertil Soc J. 2017, 22:313-6. 10.1016/j.mefs.2017.05.007

2. Statista. Polycystic ovary syndrome issues among women across India during 2020, by age group . (2021). Accessed: July 8, 2021: https://www.statista.com/statistics/1136572/india-polycystic-ovary-syndromeissues-among-women-by-age-group/.

3. Revised 2003 consensus on diagnostic criteria and long-term health risks related to polycystic ovary syndrome. Fertil Steril. 2004, 81:19-25. 10.1016/j.fertnstert.2003.10.004

4. Howkins J, Bourne G: Disorders of the ovary. Shaw's Textbook of Gynaecology, 16th Edition. Padubidri VG, Daftary SN (ed): eed Reed Elsevier India Private Limited, New Delhi; 2014. 429-34.

5. Dludla PV, Mazibuko-Mbeje SE, Nyambuya TM, et al.: The beneficial effects of N-acetyl cysteine (NAC) against obesity associated complications: a systematic review of pre-clinical studies. Pharmacol Res. 2019, 146:104332. 10.1016/j.phrs.2019.104332 
6. CDC: Reproductive health - infertility FAQs . (2021). Accessed: April 13, 2021 : https://www.cdc.gov/reproductivehealth/infertility/.

7. Aldini G, Altomare A, Baron G, Vistoli G, Carini M, Borsani L, Sergio F: N-Acetylcysteine as an antioxidant and disulphide breaking agent: the reasons why. Free Radic Res. 2018, 52:751-62. 10.1080/10715762.2018.1468564

8. Shetty R, Udupa N, Mutalik S, Kulkarni V, Rao V: Mechanisms and therapeutics of n-acetylcysteine: a recent update. Res J Pharm Technol. 2019, 12:2584-8. 10.5958/0974-360X.2019.00434.7

9. Pei Y, Liu H, Yang Y, Yang Y, Jiao Y, Tay FR, Chen J: Biological activities and potential oral applications of N-acetylcysteine: progress and prospects. Oxid Med Cell Longev. 2018, 2018:2835787. $10.1155 / 2018 / 2835787$

10. Sak S, Uyanikoglu H, Incebiyik A, Incebiyik H, Hilali NG, Sabuncu T, Sak E: Associations of serum fetuin-A and oxidative stress parameters with polycystic ovary syndrome. Clin Exp Reprod Med. 2018, 45:116-21. 10.5653/cerm.2018.45.3.116

11. Macut D, Bjekić-Macut J, Savić-Radojević A: Dyslipidemia and oxidative stress in PCOS. Front Horm Res. 2013, 40:51-63. 10.1159/000341683

12. Shahrokhi SA, Naeini AA: The association between dietary antioxidants, oxidative stress markers, abdominal obesity and poly-cystic ovary syndrome: A case control study. J Obstet Gynaecol. 2020, 40:77-82. 10.1080/01443615.2019.1603215

13. Lu J, Wang Z, Cao J, Chen Y, Dong Y: A novel and compact review on the role of oxidative stress in female reproduction. Reprod Biol Endocrinol. 2018, 16:80. 10.1186/s12958-018-0391-5

14. Artimani T, Karimi J, Mehdizadeh M, et al.: Evaluation of pro-oxidant-antioxidant balance (PAB) and its association with inflammatory cytokines in polycystic ovary syndrome (PCOS). Gynecol Endocrinol. 2018, 34:148-52. 10.1080/09513590.2017.1371691

15. Costello MF, Shrestha B, Eden J, Johnson NP, Sjoblom P: Metformin versus oral contraceptive pill in polycystic ovary syndrome: a Cochrane review. Hum Reprod. 2007, 22:1200-9. 10.1093/humrep/dem005

16. Enechukwu CI, Onuegbu AJ, Olisekodiaka MJ, et al.: Oxidative stress markers and lipid profiles of patients with polycystic ovary syndrome in a Nigerian tertiary hospital. Obstet Gynecol Sci. 2019, 62:335-43. 10.5468/ogs.2019.62.5.335

17. Del Rio D, Stewart AJ, Pellegrini N: A review of recent studies on malondialdehyde as toxic molecule and biological marker of oxidative stress. Nutr Metab Cardiovasc Dis. 2005, 15:316-28. 10.1016/j.numecd.2005.05.003

18. Bannigida DM, Nayak BS, Vijayaraghavan R: Insulin resistance and oxidative marker in women with PCOS . Arch Physiol Biochem. 2020, 126:183-6. 10.1080/13813455.2018.1499120

19. Liu Y, Yu Z, Zhao S, Cheng L, Man Y, Gao X, Zhao H: Oxidative stress markers in the follicular fluid of patients with polycystic ovary syndrome correlate with a decrease in embryo quality. J Assist Reprod Genet. 2021, 38:471-7. 10.1007/s10815-020-02014-y

20. Sulaiman MA, Al-Farsi YM, Al-Khaduri MM, Saleh J, Waly MI: Polycystic ovarian syndrome is linked to increased oxidative stress in Omani women. Int J Womens Health. 2018, 10:763-71. 10.2147/IJWH.S166461

21. Jeelani H, Ganie MA, Masood A, et al.: Assessment of PON1 activity and circulating TF levels in relation to BMI, testosterone, HOMA-IR, HDL-C, LDL-C, CHO, SOD activity and TAC in women with PCOS: an observational study. Diabetes Metab Syndr. 2019, 13:2907-15. 10.1016/j.dsx.2019.08.001

22. Moti M, Amini L, Mirhoseini Ardakani SS, Kamalzadeh S, Masoomikarimi M, jafarisani M: Oxidative stress and anti-oxidant defense system in Iranian women with polycystic ovary syndrome . Iran J Reprod Med. 2015, 13:373-8.

23. Snider AP, Wood JR: Obesity induces ovarian inflammation and reduces oocyte quality . Reproduction. 2019, 158:R79-90. 10.1530/REP-18-0583

24. Lai Q, Xiang W, Li Q, et al.: Oxidative stress in granulosa cells contributes to poor oocyte quality and IVF-ET outcomes in women with polycystic ovary syndrome. Front Med. 2018, 12:518-24. 10.1007/s11684-0170575-y

25. Cheraghi E, Soleimani Mehranjani M, Shariatzadeh SM, Nasr Esfahani MH, Alani B: N-acetylcysteine compared to metformin, improves the expression profile of growth differentiation factor- 9 and receptor tyrosine kinase c-kit in the oocytes of patients with polycystic ovarian syndrome. Int J Fertil Steril. 2018, 11:270-8. 10.22074/ijfs.2018.5142

26. Liu K: Stem cell factor (SCF)-kit mediated phosphatidylinositol 3 (PI3) kinase signaling during mammalian oocyte growth and early follicular development. Front Biosci. 2006, 11:126-35. 10.2741/1785

27. Cheraghi E, Mehranjani MS, Shariatzadeh MA, Esfahani MH, Ebrahimi Z: N-acetylcysteine improves oocyte and embryo quality in polycystic ovary syndrome patients undergoing intracytoplasmic sperm injection: an alternative to metformin. Reprod Fertil Dev. 2016, 28:723-31. 10.1071/RD14182

28. Teimouri B, Mollashahi S, Paracheh M, Farzaneh F: Comparison of the effect of letrozole alone with letrozole plus n-acetylcysteine on pregnancy rate in patients with polycystic ovarian syndrome: a randomized clinical trial. Int J Women's Health Reprod Sci. 2021, 9:75-9. 10.15296/ijwhr.2021.13

29. Hassan M, Alalfy M, Hassan H and Ogila A: Combined n-acetylcysteine and clomiphene citrate for ovulation induction in polycystic ovary syndrome, a Double Blind Randomized Controlled Trial. Austin J Obstet Gynecol. 2019, 6:1134.

30. Mostajeran F, Tehrani HG, Rahbary B: N-acetylcysteine as an adjuvant to letrozole for induction of ovulation in infertile patients with polycystic ovary syndrome. Adv Biomed Res. 2018, 7:100. 10.4103/abr.abr_157_17

31. Maged AM, Elsawah H, Abdelhafez A, Bakry A, Mostafa WA: The adjuvant effect of metformin and Nacetylcysteine to clomiphene citrate in induction of ovulation in patients with polycystic ovary syndrome. Gynecol Endocrinol. 2015, 31:635-8. 10.3109/09513590.2015.1037269

32. Salehpour S, Sene AA, Saharkhiz N, Sohrabi MR, Moghimian F: N-acetylcysteine as an adjuvant to clomiphene citrate for successful induction of ovulation in infertile patients with polycystic ovary syndrome. J Obstet Gynaecol Res. 2012, 38:1182-6. 10.1111/j.1447-0756.2012.01844.x

33. Nasr A: Effect of N-acetyl-cysteine after ovarian drilling in clomiphene citrate-resistant PCOS women: a 


\section{Cureus}

pilot study. Reprod Biomed Online. 2010, 20:403-9. 10.1016/j.rbmo.2009.12.012

34. Rizk AY, Bedaiwy MA, Al-Inany HG: N-acetyl-cysteine is a novel adjuvant to clomiphene citrate in clomiphene citrate-resistant patients with polycystic ovary syndrome. Fertil Steril. 2005, 83:367-70. 10.1016/j.fertnstert.2004.07.960

35. Thakker D, Raval A, Patel I, Walia R: N-acetylcysteine for polycystic ovary syndrome: a systematic review and meta-analysis of randomized controlled clinical trials. Obstet Gynecol Int. 2015, 2015:817849. $10.1155 / 2015 / 817849$ 